\title{
Effect of cold versus heat modalities on dynamic balance in healthy adolescents
}

\author{
DOI: https://doi.org/10.5114/pq.2020.100279
}

\author{
Yomna F. Ahmed', Marian M. Shafeek², Shimaa T. Abu El-Kasem ${ }^{3}$ \\ ${ }^{1}$ Department of Physical Therapy for Basic Sciences, Faculty of Physical Therapy, Modern University for Technology \\ and Information, Cairo, Egypt \\ 2 Department of Physical Therapy for Paediatrics and Its Surgery, Faculty of Physical Therapy, Modern University \\ for Technology and Information, Cairo, Egypt \\ ${ }^{3}$ Department of Physical Therapy for Basic Sciences, Faculty of Physical Therapy, Cairo University, Cairo, Egypt
}

\section{Abstract}

Introduction. Many adolescents are treated with cold or heat modalities before therapeutic exercise, but the difference between the effect of cold vs. heat on dynamic balance is not clear till now. The study aimed to determine the immediate effects of cold and heat modalities for ankle joint on dynamic balance and also to compare the impact of these modalities on dynamic balance. Methods. The study involved 30 normal adolescents of both genders aged 13-18 years. The Biodex system was used for dynamic balance assessment in each participant under 3 conditions: (1) control condition: at room temperature; (2) immediately after a 15 -minute cold immersion $\left(5^{\circ} \mathrm{C} \pm 1^{\circ} \mathrm{C}\right)$ for ankle joint; (3) immediately after a 15 -minute heat immersion $\left(40^{\circ} \mathrm{C} \pm 5^{\circ} \mathrm{C}\right)$ for ankle joint. For randomization, the order of cold and heat modalities was chosen randomly by using a coin flip.

Results. Mixed design MANOVA revealed statistically significant changes in dynamic balance, including overall stability (OAS), anteroposterior stability (AP), and mediolateral stability (ML) after cold modality and after heat modality $(p \leq 0.05)$. The pairwise comparison test to compare cold vs. heat modalities determined that OAS, AP, and ML were statistically significantly improved after heat modality in comparison with cold modality $(p \leq 0.05)$.

Conclusions. Dynamic balance could be altered immediately after cold or heat modalities. It improved after heat while decreased after cold modality in healthy adolescents.

Key words: cold modality, heat modality, dynamic balance, adolescent

\section{Introduction}

Cold and heat modalities are commonly utilized in sport and rehabilitation to manage injuries during immediate and rehabilitative stages [1]. Cryotherapy and thermotherapy are useful modalities for the treatment of musculoskeletal injuries and soft tissue injuries, with the benefits of decreasing pain in joint, muscle, as well as other soft tissues [2, 3].

Immersing in cold water is one of the cryotherapy modalities especially used for distal joints for acute and chronic injuries during rehabilitation with the aim of reducing pain, decreasing oedema, and controlling inflammation [1, 4]. Despite all these benefits of cryotherapy, many authors report a decrease in performance - in muscle strength, nerve conduction velocity, running speed, vertical jump height, and agility immediately after cryotherapy treatment [2, 4-6].

Heat modality through immersion in hot water is one of the thermotherapy modalities [7]. The therapeutic effects of heat include increasing the extensibility of collagen tissues, reducing pain, relieving muscle spasms, reducing inflammation, increasing blood flow, and aiding in the post-acute phase of healing $[1,2]$.

Balance is defined as the ability to keep up the line of gravity (vertical line from centre of mass) of the body inside the base of support with less amount of postural sway [8, 9]. The ability to preserve postural control or balance is significant for carrying out all daily activities, ranging from standing and walking to sitting and standing up from a seat [10].
Impaired balance is the strongest predictor of falls [11]. Dynamic standing balance assessment is considered one of the most appropriate assessments which represent the demands of the lower extremity during functional tasks [12].

Dynamic balance is influenced by strength, flexibility, and coordination [13, 14]. Studies have found that tissue extensibility and flexibility increase after heat modalities [15] and decrease after cold modalities [16]; consequently, dynamic balance may be altered immediately after cold or heat modalities. Previous studies that investigated the effect of cold modalities on balance in adult subjects provide different results. Many report no adverse effects on balance [17-21] and others suggest that cryotherapy has a negative (harmful) impact on balance [14, 22-24]. The effect of cold or heat modalities on dynamic balance in children, especially adolescents, has not been scientifically explored yet. If the balance is altered after therapeutic applications of cold or heat, it is possible to cause injury during rehabilitation.

Findings from this study may assist clinicians in decision making regarding the use of cold vs. heat modalities within a treatment session or when considering a return of adolescents to sports after injury by using cryotherapy to reduce pain.

The study aimed to determine the immediate effects of cold and heat modalities for ankle joint on dynamic balance and also to compare the impact of these modalities on dynamic balance in healthy adolescents.

Our study hypotheses assumed no alteration of dynamic balance immediately after therapeutic applications of cold, no

Correspondence address: Marian M. Shafeek, Department of Physical Therapy for Paediatrics and Its Surgery, Faculty of Physical Therapy, Modern University for Technology and Information, El-Moustashar Mohammed Mostafa, El-Basatin Sharkeya, Qism El-Khalifa, Cairo, Egypt, e-mail: marian.magdy2001@gmail.com

Received: 12.12 .2019

Accepted: 23.04 .2020

Citation: Ahmed YF, Shafeek MM, Abu El-Kasem ST. Effect of cold versus heat modalities on dynamic balance in healthy adolescents. Physiother Quart. 2021;29(2):56-61; doi: https://doi.org/10.5114/pq.2020.100279. 
alteration of dynamic balance immediately after therapeutic applications of heat, and no difference between cold vs. heat application effects on dynamic balance in healthy adolescents.

\section{Subjects and methods}

\section{Design}

A crossover (single repeated measurements) design was used in the study to determine the immediate effects of cold and heat modalities for ankle joint on dynamic balance and also test the differences between the impact of these modalities on dynamic balance. The study was conducted from July 2019 to August 2019.

\section{Participants}

Thirty normal adolescents (15 males and 15 females) aged 13-18 years were recruited through distributing posters and online social media. They were selected in accordance with the following criteria: body mass index normal for age and sex, normal muscle strength in lower limbs. Subjects were excluded if they had cold sensitivities, any foot or ankle injury, cardiovascular abnormalities, injury or inflammation of the skin area of ankles or feet, impaired sensation in a lower limb, deficits in balance, or proprioceptive deficits; professional athletes were also excluded (Figure 1).

\section{Instrumentation}

1. For balance assessment, a Biodex system (Biodex Medical Systems Inc., Shirley, NY, USA) (serial No.: 13020193) was used. The device is computerized to be automatically calibrated before each measurement. It consists of a circular foot platform of 21.5 inches in diameter that permits $20^{\circ}$ tilting in all directions, support rails (height-adjustable), a display screen (height-adjustable), and a printer (Figure 2). The Biodex system is a valid and reliable objective measurement tool for balance assessment [25]. The device has 12 dynamic levels of measurement plus locked for static measurements.

2. $\mathrm{Na}$ alcohol laboratory thermometer with a range between $-10^{\circ} \mathrm{C}$ and $110^{\circ} \mathrm{C}$ was applied to accurately measure the temperature of water used in the heat and cool bath.

3. A water tank of suitable size was utilized for cold and heat bath.

\section{Procedures}

The study procedures were carried out at the laboratory of biomechanics, Faculty of Physical Therapy, Modern University for Technology and Information, Cairo, Egypt. All test procedures were explained to each subject before their participation. Firstly, each participant performed a posture stability test at controlled room temperature of $25^{\circ} \mathrm{C}$ (control situation) with the use of the Biodex balance system [26]. Then, the same tests were repeated 2 times (immediately after 15 minutes of cold or heat modalities application), with a 24-72-hour interval between the 2 modalities (experiment situation). The order of cold or heat modalities was randomized by using a coin flip.

For the dynamic balance assessment, each participant was asked to stand barefoot at the Biodex platform. Their name, age, and height were entered. Then, the type of test was selected, which was postural stability test. The level of stability was adjusted at the $7^{\text {th }}$ level for 10 seconds (test period). The participant was asked to stand on their dominant foot with arms held at the sides and closed eyes and try to control their balance as much as possible. The measurement data included anteroposterior stability index, mediolateral stability index, and overall stability index. A stability index is the capacity of the subject to control the degree of platform tilt. An increasing index value indicates considerable motion and high amount of sway, which implies a balance problem [27]. Two test trials were performed before the assessment and data collection for each participant to become familiar with the test procedures. Three trials were carried out for each measurement and the mean was obtained by the Biodex system (Figure 3).

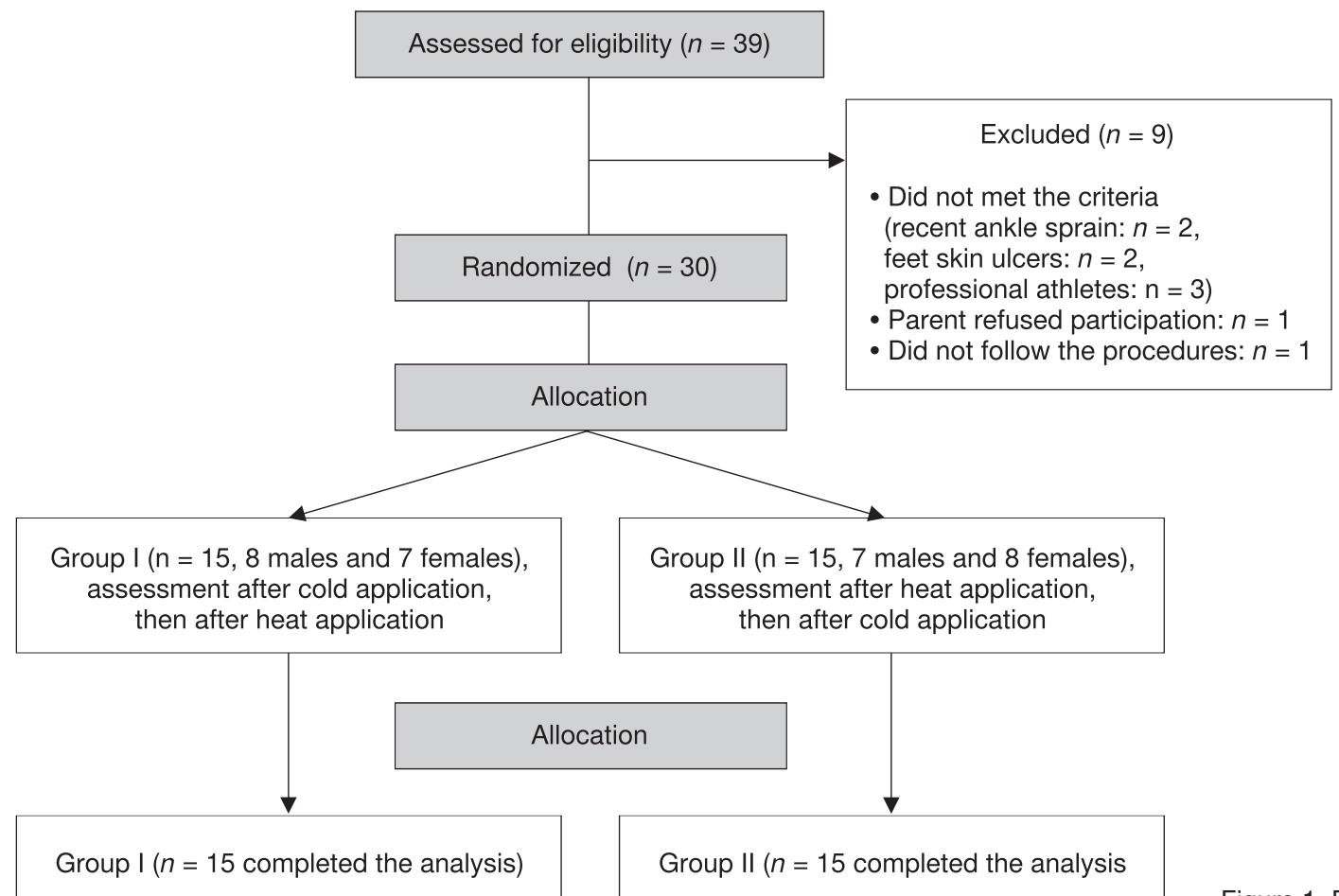




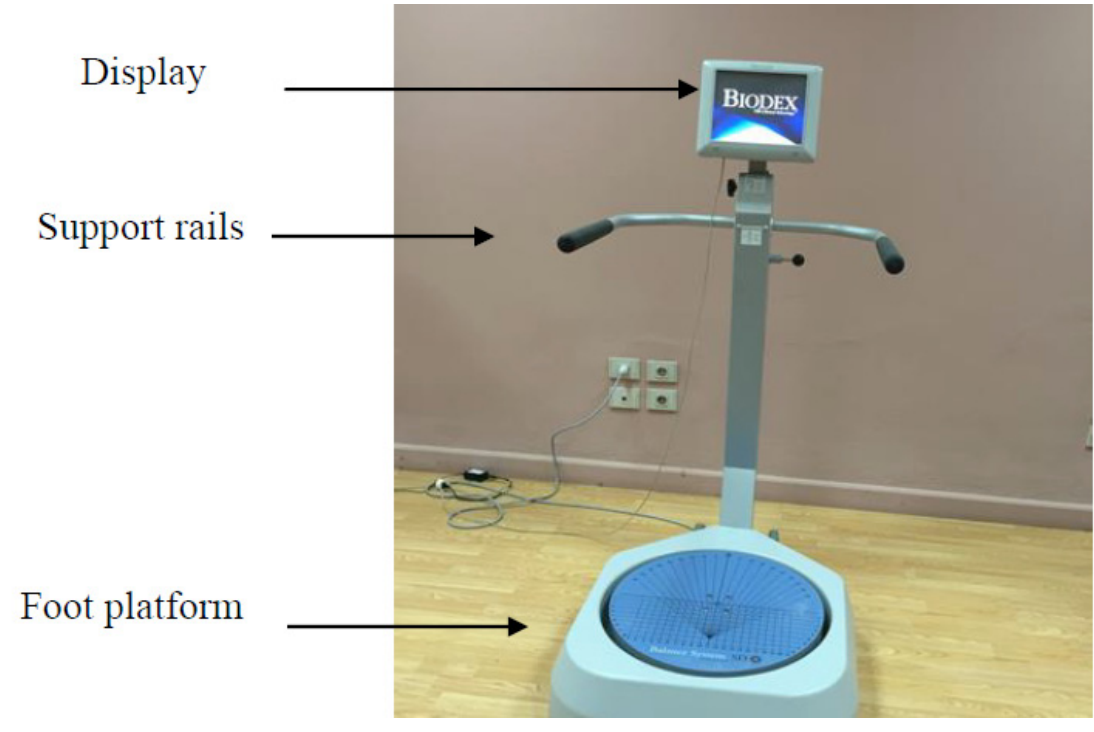

A
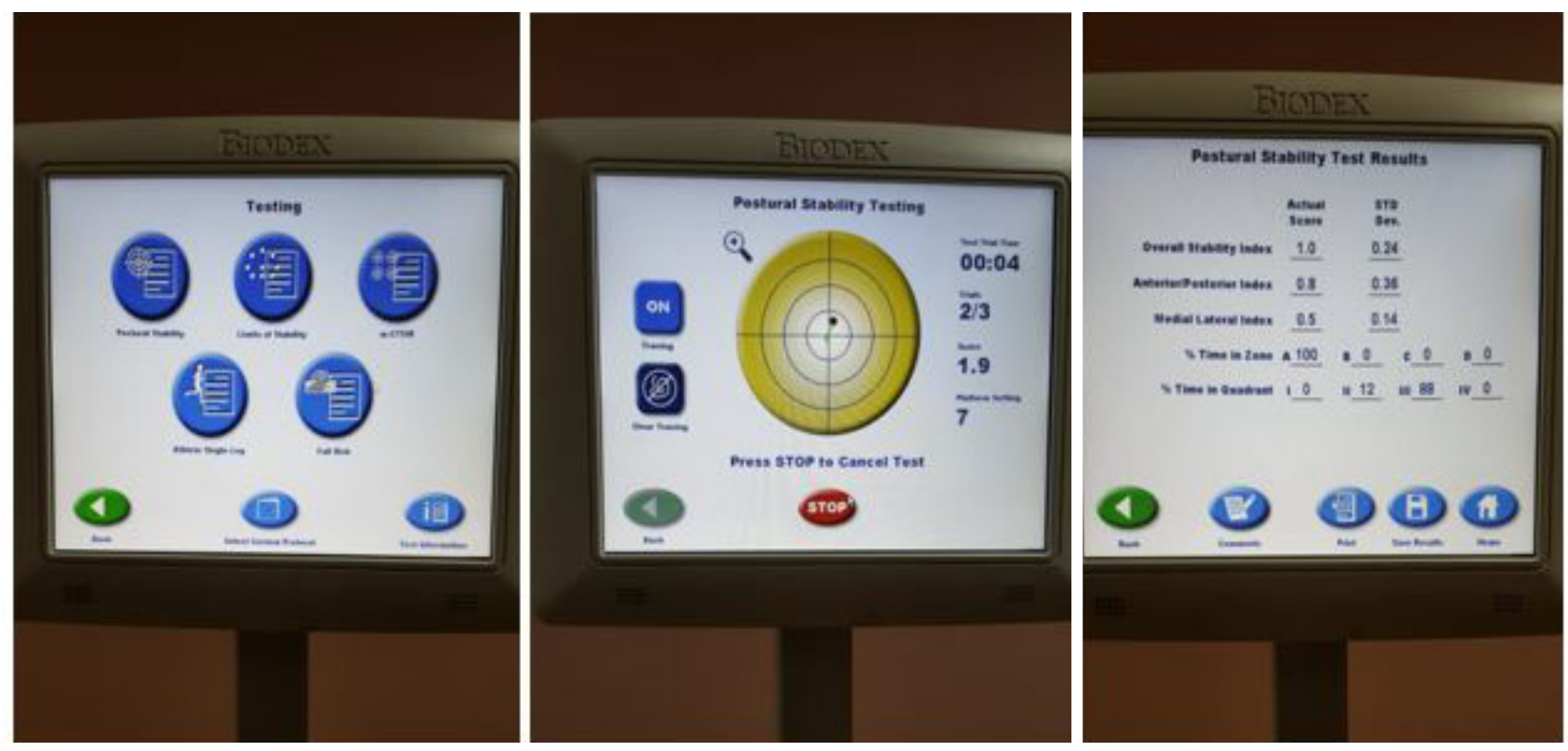

Figure 3. Pre-test $(A)$, test $(B)$, and post-test $(C)$ screen of Biodex balance system

The measurements were repeated for 3 conditions: control situation, immediately after cold modality, and immediately after heat modality, with 24-72-hour intervals between cold and heat modalities. Reports were gained and printed for each trial, including overall stability index, anteroposterior stability index, and mediolateral stability index.

\section{Application of cold modality}

A tank with cold water at the temperature of $5^{\circ} \mathrm{C} \pm 1^{\circ} \mathrm{C}$ was used to apply cold modality in this study. An alcohol laboratory thermometer served to measure the water temperature, which was adjusted as necessary by adding crushed ice. The ankle joint of the dominant extremity was immersed in the water tank for 15 minutes.

\section{Application of heat modality}

A tank with hot water at the temperature of $40^{\circ} \mathrm{C} \pm 5^{\circ} \mathrm{C}$ was used to apply heat modality in this study. The same al- temperature, which was adjusted as necessary by adding hot water. The ankle joint of the dominant extremity was immersed in the water tank for 15 minutes.

\section{Sample size}

The appropriate sample size was determined by using a pre-post comparison of the subjects' responses, at the effect size of 0.39 , power of $80 \%$, and significance level of $5 \%$. The appropriate sample size was 28 subjects.

\section{Statistical analysis}

Data analysis was performed with the SPSS 25 for Windows statistical software. The normality of data distribution was tested with the Shapiro-Wilk test and a normal distribution was established. Descriptive data for participants, characteristics, and dependent variables were calculated as mean $\pm S D$. Mixed model MANOVA served to assess the statistically significant effects of the 2 modalities (cold and heat) on overall stability (OAS), anteroposterior stability (AP), and me- 
diolateral stability $(\mathrm{ML})$ compared with baseline for all the subjects. The alpha level of significance was adopted at 0.05 .

\section{Ethical approval}

The research related to human use has complied with all the relevant national regulations and institutional policies, has followed the tenets of the Declaration of Helsinki, and has been approved by the Research Ethical Committee, Faculty of Physical Therapy, Cairo University, Egypt (approval No.: P.T.REC/012/002419) and registered in the Pan African ClinicalTrials Registry (registrationNo.:PACTR201907751587389).

\section{Informed consent}

Informed consent to participation and publication of the results has been obtained from one parent of each participant included in this study.

\section{Results}

Thirty volunteers of both genders participated in the study. The subjects' baseline characteristics were expressed by descriptive statistics (mean and $S D$ ) and presented in Table 1.

Regarding OAS, there was a statistically significant increase after cold immersion (the percentage of increase was $13 \%$ ) and a statistically significant decrease after heat immersion (the percentage of decrease was $7.8 \%$ ). Pairwise

Table 1. Characteristics of study participants (mean $\pm S D$ )

\begin{tabular}{|c|c|c|}
\hline \multicolumn{2}{|l|}{ Variable } & Volunteers \\
\hline \multicolumn{2}{|c|}{ Age (years) } & $15.2 \pm 1.71$ \\
\hline \multicolumn{2}{|c|}{ Weight (kg) } & $54.9 \pm 6.13$ \\
\hline \multicolumn{2}{|c|}{ Height (m) } & $159.7 \pm 4.28$ \\
\hline \multicolumn{2}{|c|}{ Body mass index } & $21.483 \pm 1.346$ \\
\hline \multirow{2}{*}{ Gender } & Males & $15(50 \%)$ \\
\hline & Females & 15 (50\%) \\
\hline
\end{tabular}

comparison was used to compare 3 levels of measurement (pre, post-cold, and post-hot). It revealed a statistically significant difference between the 3 measurements. By comparing the mean difference between the 3 measurements, we can conclude that OAS was improved significantly after heat immersion in comparison with cold immersion, as shown in Table 2 and Figure 4.

Regarding AP, there was a statistically significant increase after cold immersion (the percentage of increase was $47.09 \%$ ) and a statistically significant decrease after heat immersion (the percentage of decrease was 12.79\%). Pairwise comparison was used to compare 3 levels of measurement (pre, postcold, and post-hot). It revealed a statistically significant difference between the 3 measurements. By comparing the mean difference between the 3 measurements, we can conclude that AP was improved significantly after heat immersion in comparison with cold immersion, as shown in Table 2 and Figure 4.

Regarding ML, there was a statistically significant increase after cold immersion (the percentage of increase was 37.9\%) and a statistically significant decrease after heat immersion (the percentage of decrease was 19.3\%). Pairwise comparison was used to compare 3 levels of measurement (pre, postcold, and post-hot). It revealed a statistically significant difference between the 3 measurements. By comparing the mean difference between the 3 measurements, we can conclude that $\mathrm{ML}$ was improved significantly after heat immersion in comparison with cold immersion, as shown in Table 2 and Figure 4.

\section{Discussion}

The major findings of the current study were as follows:

- Dynamic balance was decreased immediately after cold modality as there were statistically significant increases in OAS, AP, and ML $(p \leq 0.05)$.

- Dynamic balance improved immediately after heat modality as there were statistically significant decreases in OAS, $\mathrm{AP}$, and $\mathrm{ML}(p \leq 0.05)$.

Table 2. Comparison between mean values of overall stability (OAS), anteroposterior stability (AP), and mediolateral stability (ML) at pre-treatment, post-cold, post-hot, and pairwise comparisons between them

\begin{tabular}{|c|c|c|c|c|c|c|}
\hline \multirow{2}{*}{ Variable } & \multicolumn{2}{|c|}{ OAS } & \multicolumn{2}{|c|}{ AP } & \multicolumn{2}{|c|}{ ML } \\
\hline & Cold group & Hot group & Cold group & Hot group & Cold group & Hot group \\
\hline Pre & $2.67 \pm 0.54$ & $2.67 \pm 0.54$ & $1.72 \pm 0.56$ & $1.72 \pm 0.56$ & $1.45 \pm 0.63$ & $1.45 \pm 0.63$ \\
\hline Post & $3.03 \pm 0.67$ & $2.46 \pm 0.63$ & $2.53 \pm 0.53$ & $1.5 \pm 0.28$ & $2 \pm 0.14$ & $1.17 \pm 0.34$ \\
\hline Mean difference & 0.367 & -0.21 & 0.817 & -0.217 & 0.550 & -0.283 \\
\hline \multirow[t]{2}{*}{ Percentage of change } & $13 \%$ increase & $7.8 \%$ decrease & $47.09 \%$ increase & $12.79 \%$ decrease & $37.9 \%$ increase & $19.3 \%$ decrease \\
\hline & \multicolumn{2}{|c|}{ Mixed design MANOVA } & \multicolumn{2}{|c|}{ Mixed design MANOVA } & \multicolumn{2}{|c|}{ Mixed design MANOVA } \\
\hline Modalities factor & \multicolumn{2}{|c|}{$\begin{array}{c}F=46.69 \\
p=0.0001^{*}\end{array}$} & \multicolumn{2}{|c|}{$\begin{array}{l}F=136.56 \\
p=0.0001^{*}\end{array}$} & \multicolumn{2}{|c|}{$\begin{array}{c}F=61.32 \\
p=0.0001^{*}\end{array}$} \\
\hline \multirow[t]{2}{*}{ Time factor } & \multicolumn{2}{|c|}{$\begin{array}{l}F=13.38 \\
p=0.001^{*}\end{array}$} & \multicolumn{2}{|c|}{$\begin{array}{l}F=8.613 \\
p=0.006\end{array}$} & \multicolumn{2}{|c|}{$\begin{array}{l}F=12.835 \\
p=0.001^{*}\end{array}$} \\
\hline & \multicolumn{2}{|c|}{ Pairwise comparison } & \multicolumn{2}{|c|}{ Pairwise comparison } & \multicolumn{2}{|c|}{ Pairwise comparison } \\
\hline Level of measurement & Mean difference & $p$ & Mean difference & $p$ & Mean difference & $p$ \\
\hline Pre-cold vs. post-cold & -0.367 & $0.0001^{*}$ & -0.817 & $0.0001^{*}$ & -0.550 & $0.0001^{*}$ \\
\hline Pre-hot vs. post-hot & 0.21 & $0.001^{*}$ & 0.217 & $0.006^{*}$ & 0.283 & $0.001^{*}$ \\
\hline Post-cold vs. post-hot & 0.567 & $0.0001^{*}$ & 1.033 & $0.0001^{*}$ & 0.833 & $0.0001^{*}$ \\
\hline
\end{tabular}


OAS AP $\mathrm{ML}$

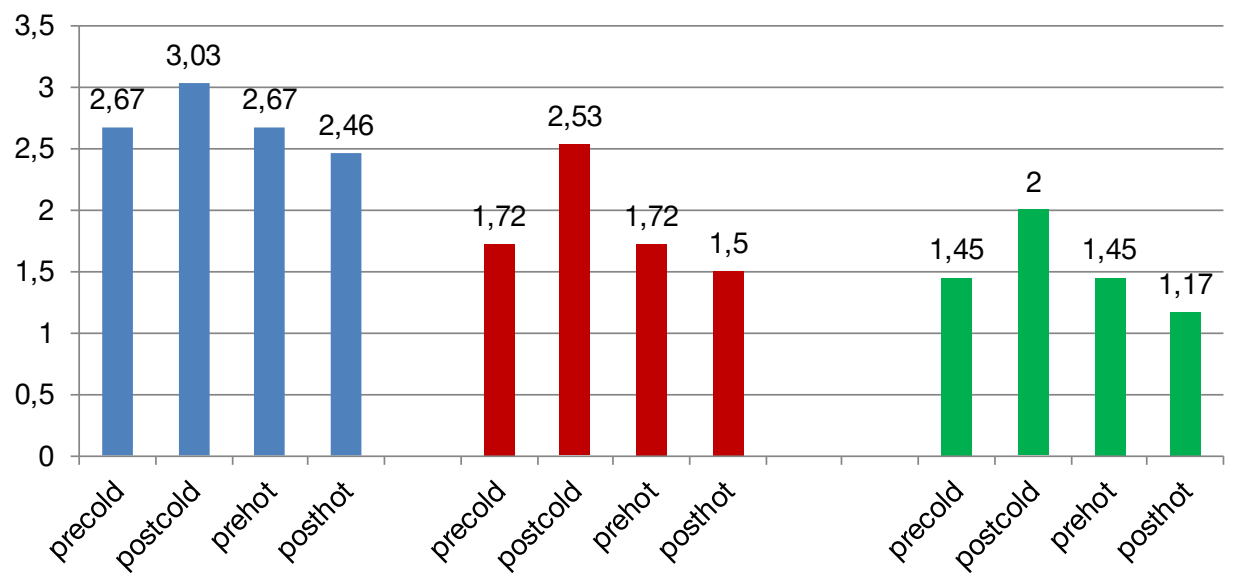

Figure 4. Mean values of overall stability (OAS), anteroposterior stability (AP), and mediolateral stability (ML) before and after both cold and heat immersion

- Heat modality significantly improved dynamic balance compared with cold modality $(p \leq 0.05)$.

\section{Cold modality}

The obtained result may be due to that the immersion in cold water therapy decreases tissue extensibility and flexibility [16], and the dynamic balance, which is the ability to perform a task while maintaining or regaining a stable position [28] or the ability to maintain or regain balance on an unstable surface $[13,29]$ with minimal extraneous motion, is influenced by strength, flexibility, and coordination [29, 30]. Therefore, decreasing dynamic balance immediately after cold modality may be due to a decrease in tissue extensibility and flexibility caused by cryotherapy.

The findings of this study come in agreement with those obtained by Fullam et al. [14] and Ahmed et al. [31], who observed that dynamic postural stability was decreased immediately after 15 minutes of ankle joint cryotherapy application. They also corroborate a study by Oliveira et al. [23], who reported that cryotherapy impaired knee joint position sense in normal knees.

The observations of this study partially agree with those obtained by Douglas et al. [22], who established - by using a Biodex balance assessment system - no statistically significant difference in overall stability index or anterior/posterior stability index of balance, as well as a statistically significant difference in medial/lateral stability index of balance after immersing the dominant ankle joint in ice water for 15 minutes.

The study results contradict those achieved by Williams et al. [20], who reported (by using a force plate) no change in balance after 20 minutes of ice bag application on the dominant leg ankle, and by Costello and Donnelly [21], who observed no evidence of an enhanced risk of injury following a return to sporting activity after cold water immersion. Also, Salehi et al. [17] found that cryotherapy through immersion of foot and ankle did not have a negative effect on the overall or anteroposterior indices of dynamic balance in athletes and non-athletes after an 8-minute ice water immersion.

\section{Heat modality}

This result may be due to that the immersion in heat water therapy increases tissue extensibility and flexibility [32], and the dynamic balance is influenced by strength, flexibility, and coordination $[29,30]$. So, the dynamic balance was af- fected by the increased tissue extensibility and flexibility caused by heat application.

The findings of this study are in agreement with those obtained by Kaynak et al. [15], who observed that joint proprioception was improved after heat modality and decreased after cold modality.

The study results contradict those achieved by Altun et al. [2], who reported no statistically significant change in jump performance after heat application, and by Mtibaa et al. [33], who found that hyperthermia impaired the measured proprioception and balance parameters.

\section{Limitations and strengths}

The sample size was limited to only 30 subjects, which may affect generalization. The study was also limited to a specific age stage (adolescents), so more research is needed for different age stages. The scarce previous research on the effect of heat on balance may affect literature. The literature on the effect of cold and heat on balance did not give clear explanations of the mechanism of cold vs. heat impact on balance.

In turn, using an objective, valid, and reliable device to measure balance in our study could be considered as a point of strength. It contributes to answering the question about the effect of cold vs. heat on balance, which has not been investigated before, especially among healthy adolescents.

\section{Conclusions}

From the obtained findings of this study, supported by literature, we could conclude that dynamic balance can be altered immediately after cold or heat modalities. It improves after heat while decreases after cold modality in healthy adolescents. These observations may assist in the decision making concerning utilization of cold or heat modalities within treatment sessions or when considering a return of athletes to sports after injury by using cryotherapy to reduce pain.

\section{Acknowledgements}

The authors are appreciative to Prof. Dr. Naguib Salem, Dean of Faculty of Physical Therapy, Modern University for Technology and Information, who permitted to perform all the study procedures in the biomechanical laboratories and medical centre of the Faculty. We are also grateful to all individuals who participated in the study. 


\section{Disclosure statement}

No author has any financial interest or received any financial benefit from this research.

\section{Conflict of interest}

The authors state no conflict of interest.

\section{References}

1. Nadler SF, Weingand K, Kruse RJ. The physiologic basis and clinical applications of cryotherapy and thermotherapy for the pain practitioner. Pain Physician. 2004; 7(3):395-399; doi: 10.36076/ppj.2004/7/395.

2. Altun M, Kaynak H, Ünal M, Özer M, Akseki D. Effect of hot and cold applications on jump performance. Turkiye Klinikleri J Sports Sci. 2014;6(1):14-23.

3. Ingersoll CD, Knight KL, Merrick MA. Sensory perception of the foot and ankle following therapeutic applications of heat and cold. J Athl Train. 1992;27(3):231-234.

4. Algafly AA, George KP. The effect of cryotherapy on nerve conduction velocity, pain threshold and pain tolerance. Br J Sports Med. 2007;41(6):365-369; doi: 10.1136/ bjsm.2006.031237.

5. Richendollar ML, Darby LA, Brown TM. Ice bag application, active warm-up, and 3 measures of maximal functional performance. J Ath Train. 2006;41(4):364-370.

6. Bleakley CM, Costello JT, Glasgow PD. Should athletes return to sport after applying ice? A systematic review of the effect of local cooling on functional performance. Sports Med. 2012;42(1):69-87; doi: 10.2165/11595970000000000-00000.

7. Prentice WE. Principles of athletic training: a competency-based approach. McGraw-Hill Education; 2013.

8. Shumway-Cook A, Anson D, Haller S. Postural sway biofeedback: its effect on reestablishing stance stability in hemiplegic patients. Arch Phys Med Rehabil. 1988;69(6): 395-400.

9. Vijayaragavan R, Perumal V. Effect of balance exercise program on static balance of male handball players at school level. Int J Phys Educ Sports Health. 2016;3(6): 285-288.

10. Refshauge KM, Kilbreath SL, Raymond J. The effect of recurrent ankle inversion sprain and taping on proprioception at the ankle. Med Sci Sports Exerc. 2000;32(1): 10-15; doi: 10.1097/00005768-200001000-00003.

11. Lubetzky-Vilnai A, Kartin D. The effect of balance training on balance performance in individuals poststroke: a systematic review. J Neurol Phys Ther. 2010;34(3):127 -137; doi: 10.1097/NPT.0b013e3181ef764d.

12. Bell DR, Guskiewicz KM, Clark MA, Padua DA. Systematic review of the balance error scoring system. Sports Health. 2011;3(3):287-295; doi: 10.1177/19417381114 03122.

13. Paillard T, Noé F. Effect of expertise and visual contribution on postural control in soccer. Scand $\mathrm{J}$ Med Sci Sports. 2006;16(5):345-348; doi: 10.1111/j.1600-0838. 2005.00502.x.

14. Fullam K, Caulfield B, Coughlan GF, McGroarty M, Delahunt E. Dynamic postural-stability deficits after cryotherapy to the ankle joint. J Athl Train. 2015;50(9):893-904; doi: 10.4085/1062-6050-50.7.07.

15. Kaynak H, Altun M, Özer M, Akseki D. Proprioception in sport and its relations with hot and cold applications [in Turkish]. CBU J Phys Edu Sport Sci. 2015;10(1):10-35.

16. White GE, Wells GD. Cold-water immersion and other forms of cryotherapy: physiological changes potentially affecting recovery from high-intensity exercise. Extrem Physiol Med. 2013;2(1):26; doi: 10.1186/2046-7648-2-26.

17. Salehi R, Zarei M, Alizadeh MH, Karimi N. Effect of lower leg cold immersion on dynamic balance of athletes and nonathletes [in Persian]. J Rehabil. 2016;17(2):148-157; doi: 10.21859/jrehab-1702148.

18. Eftekhari F, Sadeghi H, Rajabi H, Memar R, Leili AK. The effect of local cooling on knee joint position sense in healthy trained young females [in Persian]. Int J Sport Stud. 2015;5(6):700-707.

19. Wassinger CA, Myers JB, Gatti JM, Conley KM, Lephart SM. Proprioception and throwing accuracy in the dominant shoulder after cryotherapy. J Athl Train. 2007; 42(1):84-89.

20. Williams EE, Miller $3^{\text {rd }}$ SJ, Sebastianelli WJ, Vairo GL. Comparative immediate functional outcomes among cryotherapeutic interventions at the ankle. Int J Sports Phys Ther. 2013;8(6):828-837.

21. Costello JT, Donnelly AE. Effects of cold water immersion on knee joint position sense in healthy volunteers. J Sports Sci. 2011;29(5):449-456; doi: 10.1080/0264 0414.2010.544047.

22. Douglas M, Bivens S, Pesterfield J, Clemson N, Castle W, Sole $\mathrm{G}$, et al. Immediate effects of cryotherapy on static and dynamic balance. Int J Sports Phys Ther. 2013;8(1): 9-14.

23. Oliveira R, Ribeiro F, Oliveira J. Cryotherapy impairs knee joint position sense. Int J Sports Med. 2010;31(3):198201; doi: 10.1055/s-0029-1242812.

24. Surenkok $O$, Aytar $A$, Tüzün EH, Akman MN. Cryotherapy impairs knee joint position sense and balance. Isokinet Exerc Sci. 2008;16(1):69-73; doi: 10.3233/IES2008-0298.

25. Drouin JM, Valovich-McLeod TC, Shultz SJ, Gansneder BM, Perrin DH. Reliability and validity of the Biodex system 3 pro isokinetic dynamometer velocity, torque and position measurements. Eur J Appl Physiol. 2004; 91(1):22-29; doi: 10.1007/s00421-003-0933-0.

26. Bunn GP. Good manufacturing practices for pharmaceuticals, $7^{\text {th }}$ ed. Boca Raton: CRC Press; 2019.

27. Duecker JR. Measurement of validity for balance assessments using a modified CTSIB Sway Index versus a Biodex Sway Index. University of Akron; 2013.

28. Winter DA, Patla AE, Frank JS. Assessment of balance control in humans. Med Prog Technol. 1990;16(1-2): $31-51$.

29. Kioumourtzoglou E, Derri V, Mertzanidou O, Tzetzis G. Experience with perceptual and motor skills in rhythmic gymnastics. Percept Mot Skills. 1997;84(3 Pt 2):13631372; doi: 10.2466/pms.1997.84.3c.1363.

30. Davlin CD. Dynamic balance in high level athletes. Percept Mot Skills. 2004;98(3 Pt 2):1171-1176; doi: 10.2466/ pms.98.3c.1171-1176.

31. Ahmed YF, Raoof NAA, El-Sayyad MM, Amin DI. Immediate and late effect of cryotherapy on balance in healthy subjects. Int J Physiother. 2017;4(2):77-85; doi: 10.15621/ijphy/2017/v4i2/141945.

32. Simon E, Kosaka M. Application of heat and cold: physiological responses and therapeutic implications. In: Kosaka M, Sugahara T, Schmidt KL, Simon E (eds.), Thermotherapy for neoplasia, inflammation, and pain. Springer; 2001; 12-26.

33. Mtibaa K, Thomson A, Nichols D, Hautier C, Racinais S. Hyperthermia-induced neural alterations impair proprioception and balance. Med Sci Sports Exerc. 2018;50(1): 46-53; doi: 10.1249/MSS.0000000000001418. 